\title{
STUDI LITERATUR : PEMANFAATAN SENSOR TCS 230 UNTUK MEMBEDAKAN WARNA SUATU OBYEK
}

\author{
Ahmad Rofiq Hakim ${ }^{1)}$, Rizar Romiyadi' ${ }^{2}$ \\ ${ }^{1)}$ Teknologi Informasi, Politeknik Negeri Samarinda, ${ }^{2}$ Teknik Informtika, STMIK Banjarbaru \\ E-mail : rofiq93@polnes.ac.id ${ }^{1)}$, romiyadir@gmail.com ${ }^{2)}$
}

\begin{abstract}
Abstrak-Studi literatur ini dilakukan untuk memberikan gambaran mengenai sensor warna TCS 230 yang dapat dimanfaatkan dalam berbagai penelitian dan pembuatan produk atau prototipe menggunakan warna sebagai obyek yang akan disensor. Metode yang digunakan adalah deskriptip, yaitu memaparkan berbagai informasi dan hasil ujicoba mengenai sensor TCS 230 dan penggunannya pada berbgai rangkaian elektronika. Adapun hasil akhir yaitu berupa tulisan yang menjelaskan karakteristik dan penggunaan Sensor TCS 230 untuk membedakan warna
\end{abstract}

Kata kunci: Sensor, TCS 230, Warna, Obyek

\section{PENDAHULUAN}

Warna merupakan bagian dari unsur dalam kehidupan manusia, tanpa warna mungkin kehidupan manusia seperti tanpa makna. Adanya warna menyebabkan manusia dapat melihat dan merasakan sebuah keindahan.

Bebagai beda di lingkungan sekitar bahkan yang melekat ditubuh manusia juga dapat diidentifikasi karena adanya warna yang berbedabeda, selain dari bentuknya yang berbeda.

Beberapa literatur mendefinisikan warna yaitu Warna adalah spektrum tertentu yang terdapat di dalam suatu cahaya sempurna (warna putih) yang merupakan pantulan tertentu dari cahaya yang dipengaruhi oleh pigmen yang terdapat di permukaan benda. Sir Isac Newton (1704)

Ilmu tentang warna disebut chromatics. Teori warna sudah dikembangkan oleh Alberti (1435) dan diikuti oleh Leonardo da Vinci (1490). Teori warna mulai mendapat perhatian serius setelah dikembangkan oleh Sir Isac Newton (1704).[2] Pada awalnya teori warna dikembangkan dengan warna dasar merah, kuning dan biru (Red, Yellow, Blue atau RYB). Pencampuran warna dari warna dasar tersebut banyak dipakai oleh para pelukis, percetakan dan lain-lain.

Manusia memiliki perasaan dan otak untuk berfikir, sehingga mampu membedakan berbagai warna yang dilihat oleh indra mata.

Tetapi untuk suatu bentuk peralatan yang akan bekerja secara otomatis, membadakan warna bukanlah hal yang mudah. Diperlukan suato sensor untuk membedakan warna-warna dari obyek yang ada disekitarnya.

Sensor TCS 230 merupakan salah satu sensor yang dibuat oleh perusahaan TAOS.Inc di Texas yang digunakan untuk membedakan warna dengan dilengkapi dengan filter warna merah, biru dan hijau.

Studi ini membahas mengenai pemanfaatan sensor warna TCS 230 untuk meingidentifikasi warna suatu obyek.

\section{RUANG LINGKUP PENELITIAN}

Berdasarkan uraian pada latar belakang tersebut maka permasalahan dalam penelitian ini adalah "Bagaimana memanfaatkan Sensor TCS230 untuk membedakan suatu obyek",

Penelitian ini dibatasi pada ruang lingkup yaitu

1) Sensor yang digunakan adalah TCS 230 , produksi TAOS.Inc.

2) Warna obyek yang difilter adalah dominan Merah, Biru dan Hijau.

3) Perangkat pendukung pengolah data yaitu Modul Arduino Uno

\section{PENGELOMPOKKAN WARNA}

Orang mengenal warna primer dan warna sekunder. Tiryssae Newton (1642-1727) menemukan hubungan antara cahaya matahari dan warna. Ia berhasil menguraikan cahaya matahari menjadi warna merah, jingga, kuning, biru, nilai, dan ungu. Di atas merah ada warna infra merah dan dibawah warna merah warna ungu ada ultra violet. Uraian warna tersebut dinamakan spektrum. Ahli grafis Jerman Le Blond (1730) menyederhanakan temuan Newton menjadi 3 warna pokok, yaitu merah, kuning dan biru yang dinamakan warna primer.

Percampuran dua warna pokok disebut warna sekunder, yaitu merah dan biru menjadi ungu, merah dan kuning menjadi oranye, hijau dan ungu menjadi hijau ungu. Percampuran warna sekunder disebut dengan warna tersier, yaitu oranye dan ungu menjadi oranye ungu, oranye dan hijau menjadi oranye hijau, hijau dan ungu menjadi hijau ungu.

1). Warna Pokok (primer)

Warna primer adalah warna yang menjadi pedoman setiap orang untuk menggunkannya. Dalam penggunaannya warna pokok ada dua macam. Untuk grafis, yang dipakai adalah pigmen yang terdiri dari biru (cyan), merah (magenta), dan kuning (yellow). Pada foto dan grafis 
komputer, warna pokok cahaya terdiri dari red, green, dan blue (RGB). Dalam komputer, warna-warna yang pertama cyan, magenta dan yellow masih ditambahkan warna key (hitam) sehingga dikenal istilash CMYK.

2). Warna Sekunder

Warna sekunder merupakan percampuran antara warna primer.
a. Merah + biru $=$ ungu/violet
b. Merah + kuning $=$ oranye/jingga
c. Kuning + biru $=$ hijau

3).Warna Tersier

Warna tersier merupakan percampuran antara warna sekunder dengan primer.
a. Merah + ungu $=$ merah ungu
b. Ungu + biru $=$ ungu biru
c. Biru + hijau hijau biru
d. Hijau + kuning = kuning hijau
e. Kuning + oranye $=$ oranye kuning

\section{SENSOR TCS 230}

Sensor warna TCS230 adalah sensor warna yang sering digunakan pada aplikasi mikrokontroler untuk pendeteksian suatu object benda atau warna dari objet yang di monitor. Sensor warna TCS230 juga dapat digunakan sebagi sensor gerak, dimana sensor mendeteksi gerakan suatu object berdasarkan perubahan warna yang diterima oleh sensor. Pada dasarnya sensor warna TCS230 adalah rangkaian photo dioda yang disusun secara matrik array $8 \times 8$ dengan 16 buah konfigurasi photodioda yang berfungsi sebagai filter warna merah, 16 photodiode sebagai filter warna biru, 16 photodiode sebagai filter warna hijau dan 16 photo dioda lagi tanpa filter warna.

Sensor warna TCS230 merupakan sensor yang dikemas dalam chip DIP 8 pin dengan bagian muka transparan sebagai tempat menerima intensitas cahaya yang berwarna. Kontruksi sensor warna TCS230 dapat dilihat pada gambar berikut. Konstruksi Sensor Warna TCS230 Pada sensor warna TCS230 terdapat selektor S2 dan S3 yang berfungsi untuk memilih kelompok konfigurasi photodiode yang akan digunakan atau dipakai. Kombinasi fungsi S2 dan S3 dalam pemilihan kelompok photodiode adalah sebagai berikut.

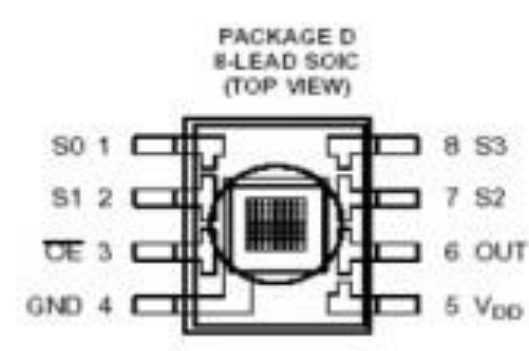

\section{Gambar 1. Sensor TCS 230 dan Blok Diagram (Datasheet TCS 230)}

Sensor TSC 230 bekeja dengan mngkonversi cahaya-ke-frekuensi warna. TCS230 yang dapat diprogram menggabungkan fotodioda silikon yang dapat dikonfigurasi dan konverter arus ke frekuensi pada sirkuit tunggal CMOS monolitik tunggal. Outputnya adalah gelombang persegi (50\% siklus kerja) dengan frekuensi berbanding lurus dengan intensitas cahaya (radiasi). Output skala penuhfrekuensi dapat diskalakan oleh salah satu dari tiga nilai preset melalui dua pin input kontrol. Input digital dan output digital memungkinkan antarmuka langsung ke mikrokontroler atau sirkuit logika lainnya. Aktifkan keluaran (OE) menempatkan keluaran dalam keadaan impedansi tinggi untuk berbagi banyak unit dari jalur input mikrokontroler.

Konverter cahaya ke frekuensi membaca array fotodioda $8 \times 8$. Enam belas fotodioda memiliki filter biru, 16 fotodioda memiliki filter hijau, 16 fotodioda memiliki filter merah, dan 16 fotodioda jelas tanpa filter.

Keempat jenis (warna) dari fotodioda adalah interdigitated untuk meminimalkan efek ketidakseragaman insiden penyinaran. Semua 16 fotodioda dengan warna yang sama terhubung secara paralel dan jenis fotodioda yang mana Penggunaan perangkat selama operasi dapat dipilih. Fotodioda berukuran $120 \mathrm{~mm}$ x $120 \mathrm{~mm}$ dan berukuran $144 \mathrm{~mm}$ pusat.

\section{1). Cara Kerja Sensor Warna}

Keluaran dari sensor warna ini yaitu berupa gelombang persegi dengan modulasi $50 \%$ yang dimana berbanding lurus dengan intensitas cahaya yang terbaca oleh sensor.

Bagian - bagian penting dari sensor warna TCS230 tertampil pada gambar dibawah 


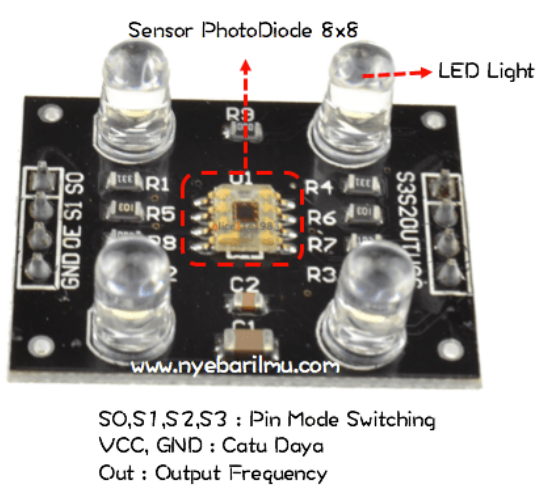

\section{Gambar 2. Modul Sensor TCS 230} Sumber : www.nyebarilmu.com

Pada sensor terdapat sebuah photodiode dengan array 8 × 8 yang mengkonversi warna menjadi frekuensi, yang terdiri dari :
a. 16 dioda untuk filter merah
b. 16 dioda untuk filter hijau
c. 16 dioda untuk filter biru
d. 16 dioda untuk clear (tanpa filter)

Dari kesemua dioda terhubung ke dalam rangkaian paralel yang menggunakan metode switching pin (S0,S1,S2,S3).

\section{2). Blok Diagram}

Pada tiap ke-16 fotodioda tersebut terhubung secara paralel, melihat gambar 3 , dengan menggunakan 2 pin kontrol S2 dan S3 dapat memilih mana yang akan dibaca. Sehingga jika mendeteksi warna merah, dapat menggunakan 16 red difference photodiodes dengan mengatur dua pin ke tingkat logika rendah.

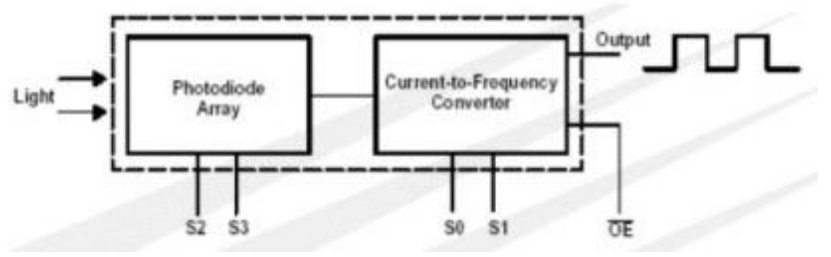

Gambar 3. Blok Diagram TCS 230 (Datasheet TCS 230)

Sensor memiliki 2 pin kontrol, S0 dan S1 yang berfungsi untuk mengukur frekuensi keluaran. Frekuensi ini dapat di adjust dengan 3 nilai preset yang berbeda yaitu $100 \%, 20 \%$ atau $2 \%$. Penskalaan frekuensi bertujuan untuk berbagai penghitung frekuensi dalam optimimalisasi keluaran sensor.

\section{ARDUINO UNO}

Ardunio UNO adalah salah satu sistem minimum komputer yang dapat digunakan untuk mengolah data yang berasal dari sensor warna TCS 230. Arduino UNO berupa sebuah board mikrokontroler berbasis ATmega328 (datasheet). Memiliki 14 pin input dari output digital dimana 6 pin input tersebut dapat digunakan sebagai output PWM dan 6 pin input analog, $16 \mathrm{MHz}$ osilator kristal, koneksi USB, jack power, ICSP header, dan tombol reset. Untuk mendukung mikrokontroler agar dapat digunakan, cukup hanya menghubungkan

Board Arduino Uno ke komputer dengan menggunakan kabel USB atau listrik dengan AC yang-ke adaptor-DC atau baterai untuk menjalankannya.Uno berbeda dengan semua board sebelumnya dalam hal koneksi USB-toserial yaitu menggunakan fitur Atmega8U2 yang diprogram sebagai konverter USB-to-serial berbeda dengan board sebelumnya yang menggunakan chip FTDI driver USB-to-serial.

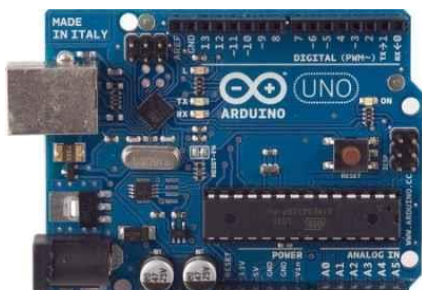

\section{Gambar 4. Arduino UNO}

\section{Konfigurasi S2 dan S3 Sensor Warna TCS230}

Sensor warna TCS230 terdapat selektor S2 dan S3 yang berfungsi untuk memilih kelompok konfigurasi photodiode yang akan digunakan atau dipakai. Kombinasi fungsi S2 dan S3 dalam pemilihan kelompok photodiode dpat dilihat pada tabel 1 .

Tabel 1. Konfigurasi filter pada S2 dan S3

\begin{tabular}{|c|c|c|}
\hline S2 & S3 & Photdioda Aktif \\
\hline 0 & 0 & Merah \\
\hline 0 & 1 & Biru \\
\hline 1 & 0 & Tanpa Filter \\
\hline 1 & 1 & Hijau \\
\hline
\end{tabular}

Photodiode akan mengeluarkan arus yang besarnya sebanding dengan kadar warna dasar cahaya yang menimpanya. Arus ini kemudian dikonversikan menjadi sinyal kotak atau pulsa digital dengan frekuensi sebanding dengan besarnya arus. Frekuensi Output ini bisa diskala dengan mengatur kaki selektor S0 dan S1. 
Penskalaan Output bisa dilihat pada tabel 2 .

Tabel 2. Penskalaan Output Sensor Warna TCS230

\begin{tabular}{c|c|c}
\hline S0 & S1 & $\begin{array}{c}\text { Skala Frekuensi } \\
\text { Output }\end{array}$ \\
\hline 0 & 0 & Power Down \\
\hline 0 & 1 & $2 \%$ \\
\hline 1 & 0 & $20 \%$ \\
\hline 1 & 1 & $100 \%$ \\
\hline
\end{tabular}

Untuk itu program untuk mendapatkan komposisi RGB adalah program penghitung frekuensi. Ada dua cara yang biasa dilakukan untuk menghitung frekuensi. Cara pertama: Kita buat sebuah timer berperiode 1 detik, dan selama periode itu kita hitung berapa kali terjadi gelombang kotak atau berapa jumlah pulsa yang diterima.

\section{UJICOBA MENGAKSES SENSOR WARNA TCS230 DENGAN LED RGB}

Kebutuhan untuk membaca data dari sensor warna TCS230 menggunakan Arduino UNO dapat dibuat seperti gambar 5 .

Adapun alat yang digunakan adalah

1) Arduino Uno

2) Sensor TCS230

3) Module Led RGB

4) Resistor $220 \Omega @ 3$ pcs

5) Kabel jumper

6) Komputer + Software Arduino IDE

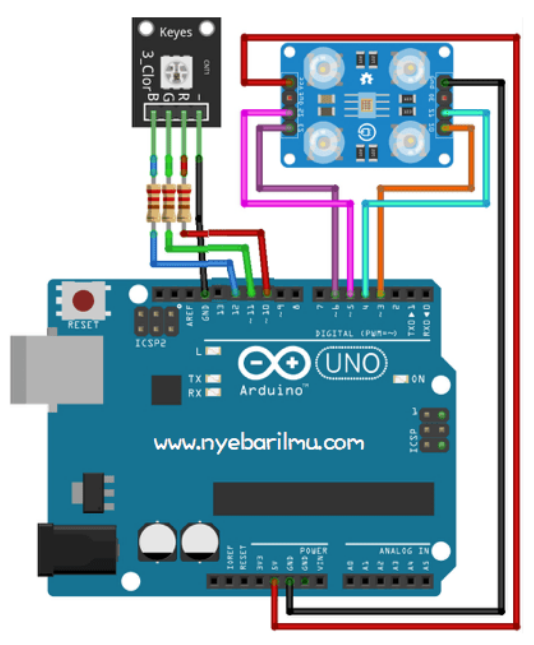

Gambar 5. Rangkaian Ujicoba Sensor Warna TCS230 dan Arduino UNO Sumber : www.nyebarilmu.com

Adapun sintak untuk ujicoba ini dapat menggunakan sintak berikut, (sumber : www.nyebarilmu.com)
// www.nyebarilmu.com

//Wiring PIN Sensor TCS3200 / TCS230

int $s 0=3$; int $s 1=4$; int $s 2=5$; int $s 3=6$; int out $=7$; // sebagai indikator Warna object telah

const int $\mathrm{LED}=13$;

void TCS3200() \{

pinMode (LED, OUTPUT)

pinMode ( 22, OUTPUT) ; pinMode (s3, OUTPUT) ; pinM ode (s 0, OUTPUT) ; pinMode (s1, OUTPUT) ;

return;

\}

void setup () \{

//Prosedur pemanggilan fungsi sensor TCS3200

$\operatorname{TCS} 3200()$;

//Setting output untuk LED RGB

pinMode (10, OUTPUT); //Warna merah

pinMode (11, OUTPUT); //warna hijau

pinMode (12, OUTPUT); //warna biru

Serial.begin(9600);

delay (200):

\}

void loop () \{

Serial.print (detectColor(out)) ;

delay (200):

\}

unsigned int detectColor(int taosOutPin) \{ double isPresentTolerance $=1$;

//range nilai tolerance yaitu 1 - 10

//Fungsi tolerance yaitu penghindar noise pembacaan sensor

double

isPresent=colorRead (taosOutPin, 0,0$) /$ colorR

ead (taosOutPin, 0,1 ) ,

Serial.print("isPresent:") ; Serial.println( isPresent, 2);

Serial.print("isPresentTolerance curently set

to:") ; Serial.println (isPresentTolerance, 2)

if (isPresent<isPresentTolerance) \{

Serial.println("nothing is in front of sensor");

return 0

\}

double red,blue, green;

double white $=$ colorRead (taosOutPin $, 0,1)$; unsigned int maxColor = white ;

unsigned int red2, blue2, green2;

//Mode pendeteksian warna merah red=white/colorRead (taosOutPin , 1,1 ); red2=r ed*255/maxColor;

//Mode pendeteksian warna hijau green=white/colorRead (taosOutPin, 3, 1) ; gree n2=green $* 255 / \operatorname{maxColor}$;

//Mode pendeteksian warna biru blue=white/colorRead (taosOutPin, 2, 1) ; blue2 $=$ blue $255 / \operatorname{maxColor}$; 
JUST TI, Volume 12 Nomor 1, Januari 2020: 22 - 26

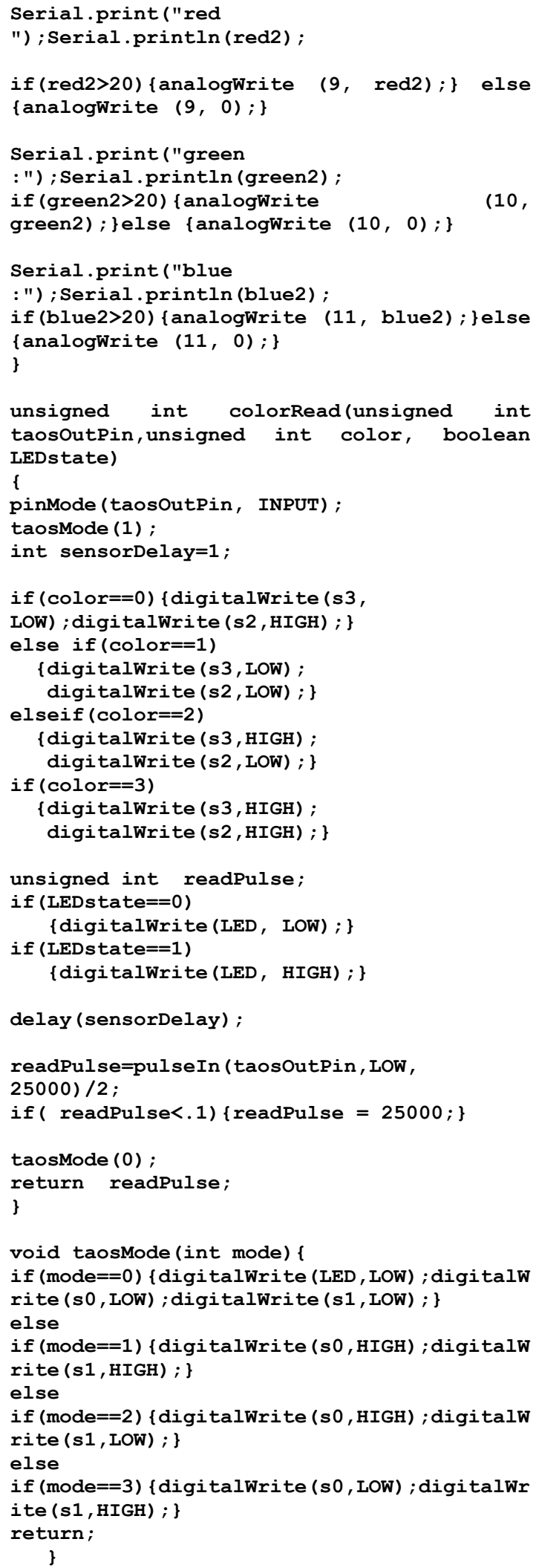

Sintak ini dapat digunakan untuk mendeteksi warna merah, hijau dan biru. Yang dalam penerapannya bisa untuk berbagai obyek seperti kertas, lantai, dinding maupun benda-benda 2 atau
3 dimensi lain yang berwarna merah, hijau dan biru.

\section{KESIMPULAN}

1) Sensor TCS230 dapat digunakan untuk mensensor warna merah, hijau dan biru.

2) Untk dapat digunakan maka perlu sistem minimumkomputer untuk membaca data dari sensor TCS230 dan mengolah data tersebut. Arduino Uno dapat digunakan sebagai sistem minimum.

3) Pemanfaatan sensor TCS230 bisa untuk mengidentifikasi berbagai obyek seperti lantai, dinding, bola dan lainnya yang berwarna merah, hijau dan biru

\section{Daftar Pustaka}

[1] Ardan, Dani., Tutorial PenggunaanTCS230, http://www.belajarduino.com/2016/12/tu torial-penggunaan-sensor-warnatcs230.html, 26 Desember 2019, pikul 11.20

[2] Taos. Inc., Data Sheet TCS230, Texas, 2003

[3] _ Cara mengakses module sensor warna TCS230 menggunakan Arduino, https://www.nyebarilmu.com/, diakses 26 Desember 2019, pukul 10.20

[4] ___Sensor TCS 230, https://elektronika-dasar.web.id/sensorwarna-tcs230/, diakses 26 Desember 2019, pukul 10.52 